\title{
NMDA and dopamine interactions in the nucleus accumbens modulate cortical acetylcholine release
}

\author{
Amy Zmarowski, ${ }^{1}$ Martin Sarter ${ }^{2}$ and John P. Bruno ${ }^{1}$ \\ ${ }^{1}$ Department of Psychology, The Ohio State University, Columbus, OH, USA \\ 2Department of Psychology, The University of Michigan, Ann Arbor, MI, USA
}

Keywords: acetylcholine, cortex, dopamine, glutamate, neuromodulation, nucleus accumbens

\begin{abstract}
The nucleus accumbens (NAC) plays a key role in directing appropriate motor output following the presentation of behaviorally relevant stimuli. As such, we postulate that accumbens efferents also participate in the modulation of neuronal circuits regulating attentional processes directed toward the identification and selection of these stimuli. In this study, $\mathrm{N}$-methyl-D-aspartate (NMDA) and D1 ligands were perfused into the shell region of the NAC of awake rats. Cortical cholinergic transmission, a mediator of attentional processes, was measured via microdialysis probes inserted into the prefrontal cortex (PFC). NMDA perfusions (150 or $250 \mu \mathrm{M}$ ) into NAC resulted in significant increases in acetylcholine (ACh) efflux in PFC (150-200\% above baseline levels). Co-administration of the D1 antagonist SCH-23390 (150 $\mu \mathrm{m})$ markedly attenuated (by approx. $70 \%)$ ACh efflux following perfusions of $150 \mu \mathrm{M}$ NMDA but not following $250 \mu \mathrm{M}$ NMDA, suggesting that D1 receptor activity contributes to the ability of the lower but not the higher concentration of NMDA to increase cortical ACh release. Collectively, these data reveal a positive modulation of NMDA receptors by D1 receptors in NAC that is expressed trans-synaptically at the level of cortical transmission. This modulation may underlie the coordinated linking of attentional processes and motor output following exposure to salient and behaviorally relevant stimuli.
\end{abstract}

\section{Introduction}

The nucleus accumbens (NAC) has long been recognized in its role as an interface between limbic input and motor output (Mogenson et al., 1980; Mogenson \& Yang, 1991; Pennartz et al., 1994; Kelley, 1999). Consistent with this role, more recent functional characterizations of the NAC have focused on the selection of appropriate behaviors in response to novel (Rebec et al., 1997; Legault \& Wise, 1999) and discriminative cues with incentive salience (Berridge \& Robinson, 1998; Neigh et al., 2004; Nicola et al., 2004a,b; Yun et al., 2004a,b). This linking of motor responses to cues that predict reward is a central feature of motivated behavior.

Recent studies have focused on the role of the NAC in directing the activity of various ensembles of projection neurons to direct motor responses following the presentation of cues that predict reward (Schultz et al., 2003; Deadwyler et al., 2004; Ghitza et al., 2004). Far less effort, however, has been directed toward the NAC's modulation of neuronal circuits contributing to the attentional processing of these discriminative cues. Through experience animals become biased to direct their limited attentional resources toward the identification, selection and processing of stimuli that are novel or have acquired incentive salience (Franken, 2003; Sarter et al., 2003; Dalley et al., 2004a).

The basal forebrain cortical cholinergic system has been repeatedly demonstrated to play a key role in the mediation of attentional processing. Administration of muscarinic antagonists results in performance deficits on tasks that require attentional processing in humans (Mauri et al., 1994; Koller et al., 2003) and laboratory animals (Chudasama et al., 2004; Chen et al., 2004). Selective lesions

Correspondence: Dr J. P. Bruno, as above.

E-mail: bruno.1@osu.edu

Received 15 April 2005, revised 5 July 2005, accepted 25 July 2005 of cholinergic inputs to cortex impair the performance of tasks that explicitly tax sustained and visuo-spatial attention in laboratory animals (McGaughy et al., 1996; Dalley et al., 2004b). Moreover, performance of these tasks is sufficient to increase the release of acetylcholine (ACh) in cortical regions (prefrontal and parietal) known to play key roles in the mediation of attentional processing (Himmelheber et al., 2000; Passetti et al., 2000; Dalley et al., 2001; Arnold et al., 2002). Recently, we have demonstrated that the magnitude of this stimulation in cortical ACh release is proportional to the degree of cognitive effort exerted in the performance of a sustained attention task (Kozak et al., 2005). Finally, a growing number of studies have reported improvements in attentional processing following nicotinic receptor agonists that, among other things, increase cortical cholinergic activity (Hahn et al., 2003; Kumari et al., 2003).

The NAC is one of several input structures that play a key role in regulating the excitability of the basal forebrain and hence cortical ACh release. Anatomically, $\gamma$-aminobutyric acid (GABA)ergic projections from the NAC terminate on cholinergic neurons within the basal forebrain (Zaborszky \& Cullinan, 1992), and $\mathrm{GABA}_{\mathrm{A}}$ receptor activity within basal forebrain affects cortical ACh release (Moore et al., 1992). Our laboratory has conducted a series of studies demonstrating the effect of various transmitter manipulations in NAC on cortical ACh release. First, perfusion of $N$-methyl-D-aspartate (NMDA), AMPA or non-selective glutamate antagonists into the shell regions of the NAC was sufficient to stimulate $\mathrm{ACh}$ release in prefrontal cortex (PFC; Neigh-McCandless et al., 2002). Second, perfusion of D2, but not D1, antagonists into the NAC shell was sufficient to block the stimulation of cortical ACh release seen following systemic administration of a benzodiazepine-selective partial inverse agonist (Moore et al., 1999). Finally, performance in a task in which consumption of a mildly aversive liquid became a 
discriminative cue for access to a highly palatable cheese treat markedly increased cortical ACh release, and this stimulated release was attenuated following perfusion of tetrodotoxin (TTX) into the shell region of the NAC (Neigh et al., 2004).

The convergence of glutamatergic and dopaminergic inputs on medium spiny GABAergic projections of NAC provides a chemoanatomical substrate for understanding the linking of discriminative cues with motor output. Glutamate inputs from PFC, amygdala and hippocampus are involved in distinguishing between different discriminative cues (Schoenbaum et al., 1998; 1999). Dopaminergic inputs from ventral tegmental area (VTA) are activated following novel or salient stimuli (Legault \& Wise, 1999; Rebec et al., 1997), particularly those cues that predict reward (Schultz et al., 2003; Nicola et al., 2004a,b). The interaction of these inputs has been best conveyed in theories speculating that dopamine selectively gates the corticolimbic inputs to NAC medium spiny neurons and results in the biasing toward certain behavioral responses at the expense of others (Pennartz et al., 1994; Nicola et al., 2004a,b; Yun et al., 2004a,b).

Guided by recent demonstrations of NAC glutamate-dopamine gating of cue-evoked goal-directed behavior (Yun et al., 2004a,b) and the clear anatomical and functional links between NAC efferents and the basal forebrain, we tested the hypothesis that NAC glutamate and dopamine receptor activity would modulate cortical ACh release. Such modulation would direct the recruitment of attentional resources, necessary for the coordinated interplay between discriminative cues in the environment and the appropriate behavioral response. More specifically, we determined whether NMDA perfusions into the NAC shell would affect cortical ACh release and, if so, whether D1 receptor activity positively modulates this effect as has been shown at several other levels of analysis (Snyder et al., 1998; O’Donnell, 1999; Vezina \& Kim, 1999; Goto \& O'Donnell, 2001b). In these experiments, different concentrations of NMDA were perfused into the shell region of the NAC, and changes in cortical ACh efflux were measured. The modulation of this effect by D1 receptors was assessed by studying the effects of NMDA co-administered with the D1 antagonist SCH-23390.

\section{Materials and methods}

\section{Subjects}

Male Fisher 344/Brown Norway F1 rats (Harlan Sprague-Dawley, Indianapolis, IN, USA) weighing between 300 and $400 \mathrm{~g}$ were utilized for all studies. Animals were maintained in a temperature- and humidity-controlled room on a $12: 12 \mathrm{~h}$ light : dark cycle (lights on: $06.30 \mathrm{~h}$ ) and individually housed in plastic cages lined with corn cob bedding (Harlan Teklad, Madison, WI, USA). Animals had access to food and water ad libitum. All procedures involving animals were approved by The Ohio State University Institutional Animal Care and Use Committee in accordance with the NIH Guide for the Care and Use of Laboratory Animals.

Three days prior to surgery, animals were acclimated to the microdialysis testing environment in clear plastic bowls $35 \mathrm{~cm}$ height $\times 38 \mathrm{~cm}$ diameter; CMA, Stockholm, Sweden) lined with corn cob bedding. Animals remained in the bowls for a minimum of $4 \mathrm{~h} /$ day, and returned to their home cages at the end of each acclimation period.

\section{Surgery}

Following their 3 days of acclimation, animals were anesthetized using isoflurane gas $\left(2 \%, 0.6 \mathrm{~L} / \mathrm{min}, \mathrm{O}_{2}\right.$ delivery) and unilaterally implanted with microdialysis guide cannulae $(0.38 \mathrm{~mm}$ o.d.; Sci Pro,
Sanborn, NY, USA) into the medial prefrontal cortex (mPFC; in $\mathrm{mm}$ from bregma: $\mathrm{AP}+4.2, \mathrm{ML} \pm 0.6, \mathrm{DV}-0.6$ with the guide tip at $20^{\circ}$ rostral) and ipsilateral NAC shell (NAC; in mm from bregma: AP $+1.3, \mathrm{ML} \pm 1.0, \mathrm{DV}-5.8$ ). The PFC was selected because its role in the top-down regulation of attentional processing (see Sarter et al., 2001) suggests that it should be affected by motivational factors mediated by mesolimbic regions such as the NAC. The shell region of the NAC was selected because it (as opposed to the NAC core) projects directly to the cholinergic-rich areas of the basal forebrain (Zaborszky \& Cullinan, 1992). Coordinates were determined from the atlas of Paxinos \& Watson (1998). Hemispheres were counterbalanced in each experiment. Cannulae were inserted with dummy stylets to prevent occlusion, and were fixed using dental cement and three stainless steel skull screws. Animals received a prophylactic dose of the antibiotic amoxicillin (100 mg/ kg) subcutaneously, and the surgical site was swabbed with a topical antibiotic ointment (lidocaine, $5 \%$ ). Animals were allowed to recover for 3 days following surgery while continuing to be acclimated daily to the testing environment.

\section{General microdialysis procedures}

Microdialysis sessions were conducted using repeated perfusions, with each animal receiving three different pharmacological manipulations, one every other day. This repeated testing paradigm has the advantage of decreasing variability among treatment conditions because each subject is able to serve as his own control. Furthermore, it allows for paradigms such as dose-response analyses, as well as agonistantagonist interactions to be studied in the same animal. The procedure has been repeatedly validated by demonstrating that basal cortical ACh efflux does not significantly change over repeated dialysis sessions, and that the effects of behavioral, pharmacological or sensory manipulations on ACh levels do not interact with dialysis sessions (Bruno et al., 1999; Nelson et al., 2002).

On the fourth day following surgery, animals were brought to the testing environment and allowed to acclimate for $30 \mathrm{~min}$ prior to insertion of microdialysis probes. Following the 30-min acclimation period, stylets were removed and probes (Sci Pro, $0.2 \mathrm{~mm}$ o.d., $3 \mathrm{~mm}$ membrane tip for $\mathrm{mPFC}, 0.2 \mathrm{~mm}$ o.d., $2.0 \mathrm{~mm}$ membrane tip for NAC) were inserted into each guide.

Probes were continuously perfused with artificial cerebral spinal fluid (aCSF) (containing, in $\mathrm{mM}$ : $\mathrm{NaCl}, 166.5 ; \mathrm{NaHCO}_{3}, 27.5 ; \mathrm{KCl}$, 2.4; $\mathrm{CaCl}_{2}, 1.2 ; \mathrm{Na}_{2} \mathrm{SO}_{4}, 0.5 ; \mathrm{KH}_{2} \mathrm{PO}_{4}, 0.5 ;$ glucose, $\left.1.0, \mathrm{pH} 6.8\right)$ at a flow rate of $1.25 \mu \mathrm{L} / \mathrm{min}$. This perfusion medium did not contain an acetylcholinesterase inhibitor. A 3-h washout period was observed after probe insertion to allow ACh efflux to reach a stable baseline that was maximally sensitive to TTX before beginning collections (Moore et al., 1992). Three distinct experiments were conducted using this general paradigm; they are described in detail as follows.

The concentrations of NMDA and SCH-23390 utilized in these microdialysis experiments were selected from a review of several studies in the literature. Local perfusions of NMDA, via reverse dialysis, in concentrations of 100-500 $\mu \mathrm{M}$ NMDA produced concentration-dependent changes in basal and stress-induced dopamine release in PFC (Del Arco \& Mora, 2001; Lorrain et al., 2003). Thus, we chose to study two concentrations of NMDA, 150 and $250 \mu \mathrm{M}$, which were in a range shown to have effects on forebrain neurochemistry. Likewise, intrahippocampal perfusions of $\mathrm{SCH}$ $23390(100-250 \mu \mathrm{M})$ attenuated NMDA-induced locomotion and dopamine release (Zornoza et al., 2005), whereas intrastriatal perfusions of SCH-23390 (10 $\mu \mathrm{M})$ attenuated NMDA-induced increases in glutamate release in substantia nigra (Marti et al., 2002). Thus, our 
selection of $150 \mu \mathrm{M} \mathrm{SCH}-23390$ was within the range of concentrations known to attenuate certain actions of NMDA.

\section{Experiment 1: the effects of a D1 antagonist on the lower concentration of NMDA}

Animals $(n=8)$ were tested three times, with a different pharmacological manipulation (vehicle-aCSF, $150 \mu \mathrm{M}$ NMDA, or $150 \mu \mathrm{M}$ $\mathrm{SCH}-23390+150 \mu \mathrm{M}$ NMDA) administered, in counterbalanced order, every other day. Following the 3-h washout period, four baseline samples were collected; 15-min collection intervals were observed with all time points. Following the four baseline collections, the syringe was switched from aCSF to one containing aCSF + the D1 antagonist, SCH-23390 (aCSF was perfused for an additional two collections in the vehicle and NMDA sessions). Following a 15-min washout, two additional collections of either aCSF or aCSF + antagonist were taken. The syringe was then switched to one containing $\mathrm{aCSF}+\operatorname{drug} \quad(150 \mu \mathrm{M}$ NMDA, $150 \mu \mathrm{M} \quad \mathrm{SCH}-23390+150 \mu \mathrm{M}$ NMDA, or aCSF vehicle). Following a 15-min washout, four additional collections were taken before switching the syringe back to one containing only aCSF. This perfusion lasted a total of $60 \mathrm{~min}$, including an initial 15-min washout period. Following the last collection, probes were removed and stylets were reinserted before returning animals to their home cages. A separate group of rats $(n=4)$ was tested once and served as timed-controls for the effects of the D1 antagonist over the entire interval in which NMDA would have been perfused. In this group, SCH-23390 $(150 \mu \mathrm{M})$ was perfused after the fourth baseline collection until the time at which drugs are typically removed and aCSF was re-introduced.

\section{Experiment 2: the effects of a D1 antagonist on the higher concentration of NMDA}

Animals $(n=9)$ were tested three times, with a different pharmacological manipulation (vehicle-aCSF, $250 \mu \mathrm{M}$ NMDA, or $150 \mu \mathrm{M}$ $\mathrm{SCH}-23390+250 \mu \mathrm{M}$ NMDA) administered, in counterbalanced order, every other day. Following the 3 -h washout period, four baseline samples were collected; 15-min collection intervals were observed with all time points. Following the four baseline collections, the syringe was switched from aCSF to one containing aCSF + the antagonist, SCH-23390 (aCSF was perfused for an additional two collections in the vehicle and NMDA sessions). Following a 15-min washout, two additional collections of either aCSF or aCSF + antagonist were taken. The syringe was then switched to one containing $\mathrm{aCSF}+$ drug $(150 \mu \mathrm{M}$ NMDA, $150 \mu \mathrm{M} \quad \mathrm{SCH}-23390+150 \mu \mathrm{M}$ NMDA, or aCSF vehicle). Following a 15-min washout, four additional collections were taken before switching back to one containing only aCSF. This perfusion lasted a total of $60 \mathrm{~min}$, including an initial 15-min washout period. Following the last collection, probes were removed and stylets were reinserted before returning animals to their home cages. A separate group of rats $(n=4)$ was tested once and served as timed-controls for the effects of the D1 antagonist over the entire interval in which NMDA would have been perfused. In this group, SCH-23390 $(150 \mu \mathrm{M})$ was perfused after the fourth baseline collection until the time at which drugs are typically removed and aCSF was re-introduced.

\section{HPLC analysis}

Dialysis samples were stored at $-80{ }^{\circ} \mathrm{C}$ until analysed using highperformance liquid chromatography (HPLC) with electrochemical detection. A volume of $15 \mu \mathrm{L}$ of each sample was injected by an autosampler (ESA, Chelmsford, MA, USA). ACh and choline were separated by a C-18 polymer column (ESA; $250 \times 3 \mathrm{~mm}$ ) using a sodium phosphate mobile phase (in $\mathrm{mM}: \mathrm{Na}_{2} \mathrm{HPO}_{4}, 100.0$; TMACl, $0.5 ; 1$-octanesulphonic acid, $2.0 ; 0.005 \%$ microbicide reagent $\mathrm{MB}$, $\mathrm{pH}=8.0$; flow rate of $0.5 \mathrm{~mL} / \mathrm{min}$ ). A pre-column immobilized enzyme reactor (IMER; ESA) was utilized to hydrolyse choline, allowing for greater separation between choline and ACh peaks. ACh and choline were then hydrolysed post-column by an additional enzyme reactor (ESA), converted to $\mathrm{H}_{2} \mathrm{O}_{2}$ (Potter et al., 1983), and quantified using a peroxidase-wired ceramic glassy carbon electrode (Model \#5041 microdialysis analytical cell, ESA), with an applied potential of $-200 \mathrm{mV}$ (Huang et al., 1995). The detection limit under these conditions was approximately $1.0 \mathrm{fmol} / 15 \mu \mathrm{L}$ injection.

\section{Histology}

Following the final microdialysis session, animals were given an overdose of sodium pentobarbital and transcardially perfused with $0.9 \%$ heparinized saline followed by $10 \%$ formalin. Brains were removed and stored in $10 \%$ formalin for $24 \mathrm{~h}$ then transferred to a $30 \%$ sucrose solution for at least 3 days. Brains were sectioned using a cryostat; $50-\mu \mathrm{m}$ sections were mounted on slides, stained using Cresyl violet, and examined under a light microscope. Subjects whose probe placements were located outside of either the mPFC or NAC shell were excluded from further analysis.

\section{Data analysis}

For each experiment, changes in basal ACh efflux (fmol/15 $\mu \mathrm{L}$ ) across sessions and treatment groups were analysed using one-way repeated-measures analyses of variance (ANOVAs). Basal efflux was then defined as the mean of the four baseline collections, and subsequent data were expressed as percent change from that mean baseline. Statistical analyses of drug effects were conducted using a two-way, within-subjects ANOVA with drug GROUP and TIME as within-subjects measures. Two-way ANOVAs were utilized to examine differences between specific treatment groups where appropriate. Oneway ANOVAs were also used to determine the time that post-drug ACh efflux levels returned to baseline where appropriate. A minimum number of $t$-tests was also utilized to examine differences between drug conditions at specific time points. Significance was defined as $P<0.05$, and the Huynh-Feldt correction was utilized to reduce Type 1 errors associated with repeated-measures ANOVAs (Vasey \& Thayer, 1987). All statistical tests were preformed using SPSS for windows (version 12.0).

\section{Results \\ Guide cannulae placements}

Figure 1 shows representative placements of these areas. Any animals whose probe placements fell outside the $\mathrm{mPFC}$ and/or the NAC shell were excluded from further analysis.

\section{Experiment 1: the effects of a D1 antagonist on a moderate concentration of NMDA}

This experiment examined the contribution of D1 receptor activity to the ability of a moderate concentration of NMDA to stimulate cortical ACh release. Figure 2 illustrates the effects of aCSF vehicle, $150 \mu \mathrm{M}$ 

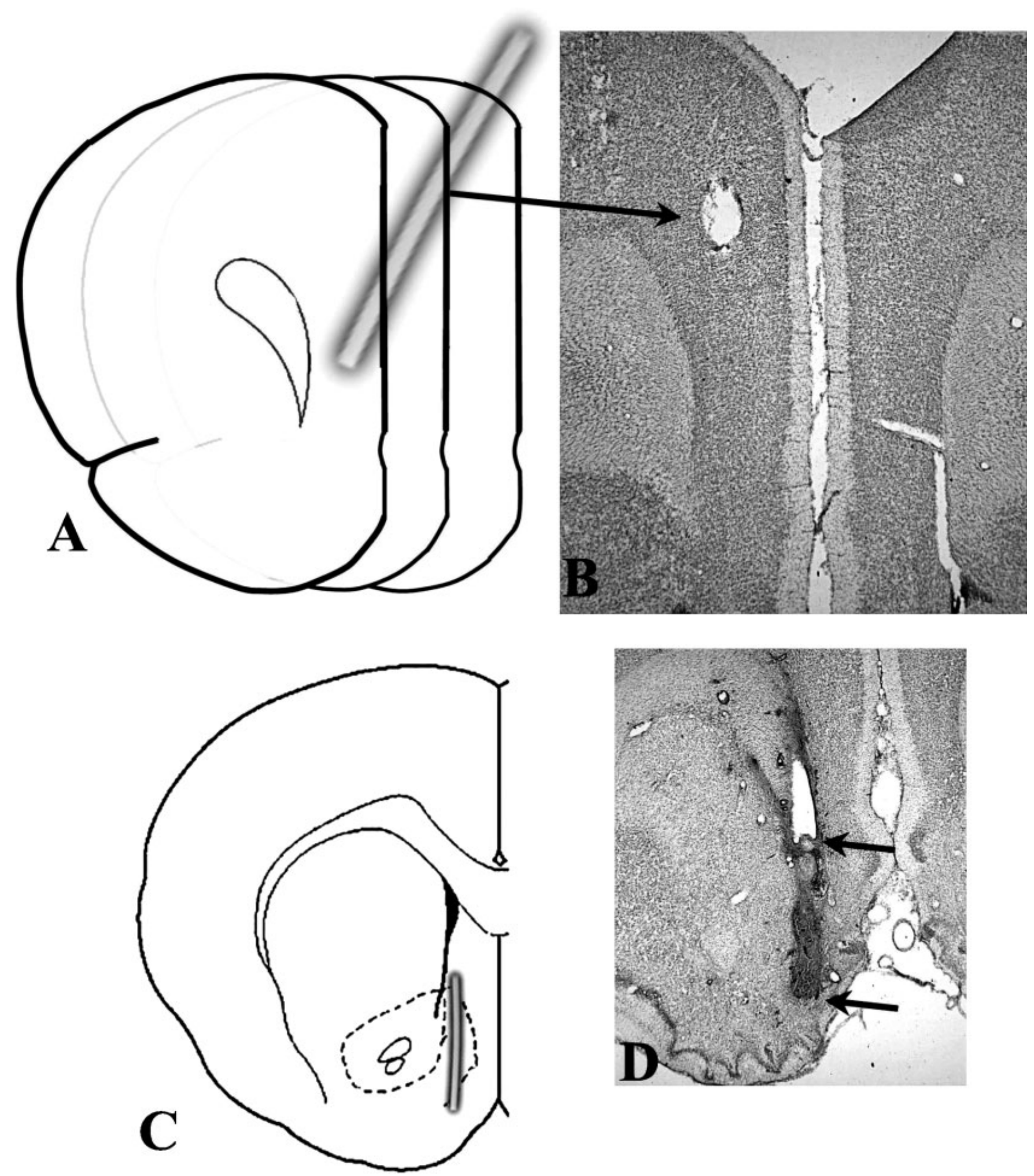

FIG. 1. (A) A schematic representation of a mPFC probe placement. Guides were implanted so that when probes were inserted, the membrane tip (3.0 mm) was located at: $\mathrm{AP}+4.2, \mathrm{ML} \pm 0.6, \mathrm{DV}-0.6$ from dura at $20^{\circ}$ rostral. (B) A photomicrograph from one of the subjects that is representative of the mPFC placement illustrated in (A). The arrow indicates the end of the guide cannula; the probe extends $3 \mathrm{~mm}$ beyond that point. (C) A schematic representation of a NAC shell probe placement. Guides were implanted so that when probes were inserted ( $2.0 \mathrm{~mm}$ active tip) the membrane tip was located at $\mathrm{AP}+1.3, \mathrm{ML} \pm 1.0, \mathrm{DV}-5.8$ from dura matter. (D) A photomicrograph from a NAC shell placement. The area between the arrows represents the active membrane tip. All of the above coordinates were calculated according to Paxinos \& Watson (1998). 


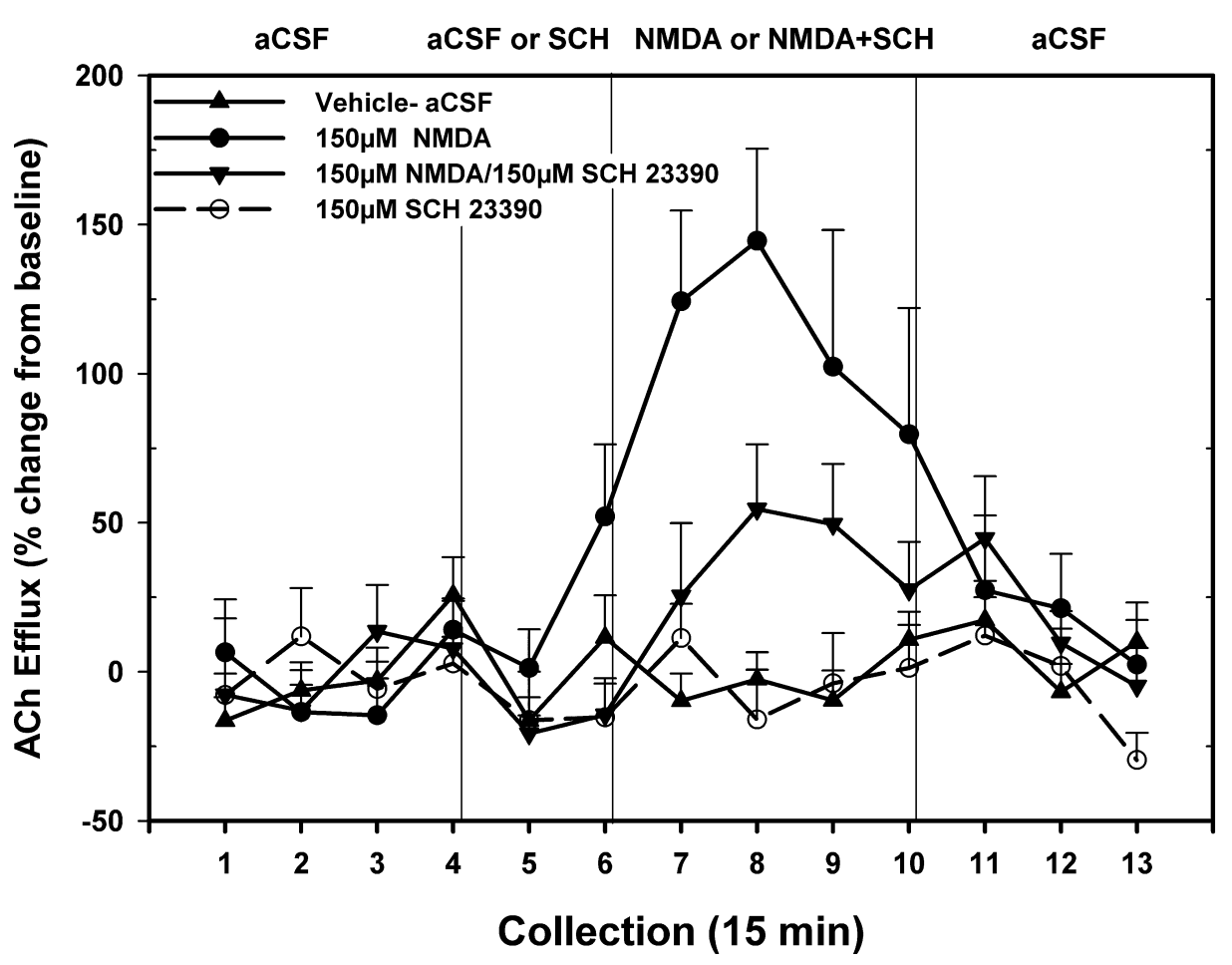

FIG. 2. Mean $( \pm \mathrm{SEM})$ acetylcholine $(\mathrm{ACh})$ efflux in the $\mathrm{mPFC}$ of animals $(n=8)$ receiving, in counterbalanced order, vehicle (artificial cerebrospinal fluid, aCSF), a moderate concentration of $N$-methyl-D-aspartate (NMDA) alone $(150 \mu \mathrm{M})$, and co-administration of a D1 antagonist SCH-23390 + NMDA into the NAC shell during three separate dialysis sessions. Following baseline collections (collections 1-4), vehicle or the antagonist was administered for 30 min (collections 5-6). This was followed by administration of aCSF + drug (vehicle, NMDA, or SCH-23390 + NMDA) for 60 min (collections 7-10). Upon conclusion of the 60-min perfusion, aCSF alone was perfused for $45 \mathrm{~min}$ until the end of the dialysis period (collections 11-13). NMDA alone significantly increased ACh efflux above vehicle, and co-administration of the D1 antagonist SCH-23390 + NMDA partially, though significantly, attenuated the effect of the moderate concentration of NMDA. A separate group of animals was tested as time-controls for the prolonged effects of perfusion of SCH-23390 (dotted line). It is clear that the extended perfusion of the D1 antagonist had no effect on cortical ACh efflux, indicating that the effect of SCH-23390 was in interaction with the administration of NMDA.

NMDA and $150 \mu \mathrm{M}$ SCH-23390 + $150 \mu \mathrm{M}$ NMDA on cortical ACh efflux $(n=8)$. Basal levels of efflux were stable over the three dialysis SESSIONs $\left(F_{2,16}=3.244, P=0.07\right)$, and across the three treatment GROUPs $\left(F_{2,16}=0.546, P=0.591\right)$, as revealed by oneway ANOVAs. Basal levels of ACh (mean \pm SEM, fmol/15 $\mu \mathrm{L}$ ) were $6.9 \pm 2.6,4.4 \pm 1.2$ and $5.9 \pm 1.5$ for aCSF, $150 \mu \mathrm{M} \mathrm{NMDA}$, and $150 \mu \mathrm{M}$ SCH-23390 + $150 \mu \mathrm{M}$ NMDA sessions, respectively. Given that basal levels of ACh efflux did not differ over session or group, all subsequent values were expressed and analysed as a percent change from session baseline. Intra-NAC perfusions of drugs led to differential effects on cortical ACh efflux (GROUP, $F_{2,14}=8.652$, $P=0.005$ ). These effects varied across collection interval (TIME, $F_{12,84}=5.958, \quad P<0.001 ; \quad$ GROUP $\times$ TIME,$\quad F_{24,168}=3.231$, $P=0.001)$. Considering the overall main effects comparing all three treatment groups, a series of smaller two-way ANOVAs was conducted to look for differences between pairs of treatment groups. Administration of $150 \mu \mathrm{M}$ NMDA significantly increased ACh levels above the vehicle aCSF session (GROUP, $F_{1,7}=11.655, P=0.011$; TIME, $F_{12,84}=4.853, \quad P<0.001 ; \quad$ GROUP $\times$ TIME,$\quad F_{12,84}=4.591$, $P<0.001)$. NMDA was significantly higher than aCSF within the first $15 \mathrm{~min}$ of perfusion (collection $7, t_{7}=-4.705, P=0.002$ ), and levels became comparable between the two treatment groups by the end of the 60-min perfusion period (collection 10, $t_{7}=-1.470$, $P=0.185$ ). Moreover, ACh levels from collection 10, in both treatment groups, were no longer elevated above their respective baseline values.

Co-administration of a D1 antagonist attenuated the NMDAinduced increases in $\mathrm{ACh}$, as efflux following $150 \mu \mathrm{M}$ NMDA differed significantly from that seen following $150 \mu \mathrm{M} \mathrm{SCH}-$
$23390+150 \mu \mathrm{M}$ NMDA (GROUP, $F_{1,7}=7.025, P=0.033$; TIME, $F_{12,84}=6.197, \quad P<0.001 ; \quad$ GROUP $\times$ TIME,$\quad F_{12,84}=2.289$, $P=0.038)$. The D1 antagonist suppressed NMDA-induced levels during collection 7 and 8 (both $P<0.05$ ). The D1 attenuation of the NMDA effect is also supported by the observation that $150 \mu \mathrm{M} \mathrm{SCH}-$ $23390+150 \mu \mathrm{M}$ NMDA did not differ from the vehicle aCSF session (GROUP, $F_{1,7}=3.395, P=0.108$ ), although there was an effect of TIME $\left(F_{12,84}=2.751, P=0.003\right)$ and a GROUP-TIME interaction $\left(F_{12,84}=2.320, P=0.013\right)$. The D1 receptor-mediated attenuation seen following co-administration of NMDA + D1 antagonist was not complete. Administration of NMDA + SCH-23390 yielded significant increases, above the aCSF vehicle session, during collections 8 and 9 (corresponding to 30 and $45 \mathrm{~min}$ of double drug perfusion). ACh efflux following perfusion of the antagonist alone (collections 5 and 6) did not differ from any of the baseline points (all $P>0.05$ ), indicating that perfusion of D1 antagonist alone did not affect ACh release. Finally, in a separate group of animals $(n=4)$ we determined the effects of SCH-23390 perfusions throughout the period during which NMDA + SCH-23390 were perfused. There was no significant deviation of ACh efflux from the aCSF control condition as the mean (SEM) efflux (\% change from baseline) was $-6.5 \pm 5.3\left(F_{12}=0.641\right.$, $P=0.793)$. These data are represented as dotted lines in Figs 2 and 3 .

\section{Experiment 2: the effects of a D1 antagonist on a higher concentration of NMDA}

This experiment determined whether D1 receptor activity contributed to the ability of a higher concentration of NMDA to stimulate cortical 


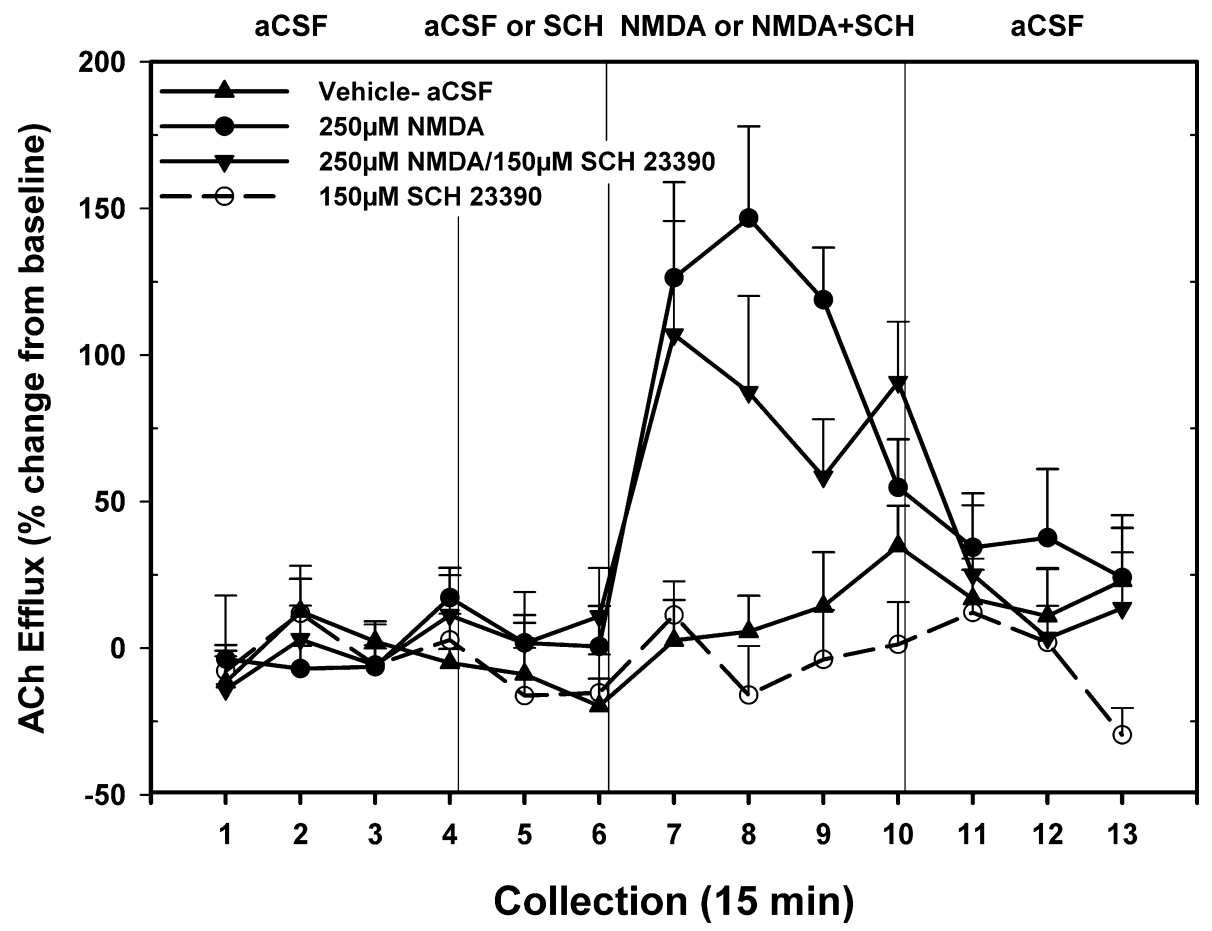

FIG. 3. Mean $( \pm \mathrm{SEM})$ acetylcholine $(\mathrm{ACh})$ efflux in the mPFC of animals $(n=9)$ receiving, in counterbalanced order, vehicle (artificial cerebrospinal fluid, aCSF), a high concentration of $N$-methyl-D-aspartate (NMDA) alone $(250 \mu \mathrm{M})$, and co-administration of a D1 antagonist SCH-23390 + NMDA into the NAC shell during three separate dialysis sessions. Following baseline collections (collections 1-4), vehicle or the antagonist was administered for 30 min (collections 5-6). This was followed by administration of aCSF + drug (vehicle, NMDA, or SCH-23390 + NMDA) for 60 min (collections 7-10). Upon conclusion of the 60-min perfusion, aCSF alone was perfused for 45 min until the end of the dialysis period (collections 11-13). NMDA alone significantly increased ACh efflux above vehicle. Unlike the case with $150 \mu \mathrm{M}$ NMDA, co-administration of the D1 antagonist SCH-23390 + 250 $\mu \mathrm{M}$ NMDA did not attenuate the effect of the high concentration of NMDA. A separate group of animals was tested as time-controls for the prolonged effects of perfusion of SCH-23390 (dotted line). It is clear that the extended perfusion of the D1 antagonist had no effect on cortical ACh efflux.

ACh efflux as it does following a more moderate concentration of NMDA (Experiment1). Figure 3 illustrates the effects of $250 \mu \mathrm{M}$ NMDA and $150 \mu \mathrm{M}$ SCH-23390 $+250 \mu \mathrm{M}$ NMDA on cortical ACh efflux $(n=9)$. Basal levels of ACh efflux were stable over both SESSIONs $\left(F_{2,16}=0.052, P=0.950\right)$, and treatment GROUPs $\left(F_{2,16}=3.089, P=0.073\right)$, as shown by a one-way ANOVA. Basal levels of ACh (mean $\pm \mathrm{SEM}$, fmol $/ 15 \mu \mathrm{L}$ ) were $7.1 \pm 1.7,4.9 \pm 0.8$ and $10.3 \pm 1.9$ for aCSF, $250 \mu \mathrm{M}$ NMDA, and the $150 \mu \mathrm{M} \mathrm{SCH}-$ $23390+250 \mu \mathrm{M}$ NMDA sessions, respectively. Given that basal levels of ACh efflux did not differ over session or group, all values were expressed as a percent change from session baseline. An overall analysis revealed significant differences among treatment groups and collection intervals (GROUP, $F_{2,16}=13.986, P<0.001$; TIME, $F_{12,96}=9.674, \quad P<0.001 ; \quad$ GROUP $\times$ TIME,$\quad F_{24,192}=2.987$, $P<0.001)$.

A series of smaller two-way ANOVAs was conducted to look for differences between pairs of treatment groups. Administration of $250 \mu \mathrm{M}$ NMDA significantly elevated ACh levels above aCSF levels (GROUP, $\quad F_{1,8}=33.164, \quad P<0.001 ; \quad$ TIME, $\quad F_{12,96}=8.533$, $P<0.001$; GROUP $\times$ TIME, $\left.F_{12,96}=5.522, P<0.001\right)$. Pairwise comparisons revealed NMDA-induced increases in ACh efflux during collections 7, 8 and 9 (all $P<0.05$ ). As was the case with the lower concentration, ACh levels fell to control aCSF values despite the continued perfusion of NMDA during collection 10 .

Three analyses support the conclusion that co-perfusion of the D1 antagonist did not attenuate the ability of the higher concentration of NMDA to stimulate ACh efflux. First, overall ACh efflux from NMDA alone did not differ from efflux induced by administration of the NMDA + SCH-23390 (GROUP, $F_{1,8}=3.883, \quad P=0.084$ ).
Second, administration of $150 \mu \mathrm{M}$ SCH- $23390+250 \mu \mathrm{M}$ NMDA significantly elevated ACh efflux above aCSF levels (GROUP, $\left.F_{1,8}=8.405, P=0.020\right)$. Levels from both $250 \mu \mathrm{M}$ NMDA alone and $250 \mu \mathrm{M}$ NMDA $+150 \mu \mathrm{M} \mathrm{SCH}-23390$ were significantly higher than those following aCSF beginning at the first post-drug time point (collection 7 , both $P<0.01$ ), but did not differ from one another ( $\left.t_{8}=0.494, P=0.635\right)$. By the end of the $60-\mathrm{min}$ perfusion period, there were no significant differences among any of the drug treatments (collection 10, all $P>0.05$ ). Finally, administration of $\mathrm{NMDA}+\mathrm{SCH}-23390$ (TIME, $F_{12,96}=4.048, P=0.001$ ) yielded significant increases relative to baseline values in this group (all $P<0.05$ ). Importantly, perfusion of the antagonist alone (collections 5 and 6) yielded no increases above any of the baseline points (all $P>0.05$ ), indicating the antagonist alone did not differentially influence ACh release.

\section{Discussion}

The aim of these studies was to test the capacity of D1 receptors in the NAC to positively modulate local glutamate activity based on the degree of NMDA receptor activation, and to determine whether this modulation could be shown trans-synaptically at the level of ACh release in $\mathrm{mPFC}$. Several major findings can be reported. First, intraaccumbens administration of either $150 \mu \mathrm{M}$ or $250 \mu \mathrm{M}$ concentration of NMDA significantly elevated ACh efflux above baseline in the mPFC. Second, the D1 receptor antagonist SCH-23390 significantly, though not completely, attenuated the effect of the lower concentration of NMDA, supporting the hypothesis of D1 receptor activity as a 
positive modulator of NMDA function. Third, the D1 antagonist was not able to attenuate ACh efflux induced by the higher concentration of NMDA, indicating that the contribution of D1 receptor activity may interact with the level of NMDA receptor activation to stimulate cortical ACh release. The following discussion will address several issues raised by these experiments.

\section{Intra-accumbens NMDA-induced increases in cortical ACh}

Our present studies illustrate that increases in NMDA receptor activity in the shell of the NAC are sufficient to increase ACh distally in the mPFC. Interestingly, there were no differences between the effects of $150 \mu \mathrm{M}$ and $250 \mu \mathrm{M}$ concentrations of NMDA; administration of each resulted in ACh increases approximately $150 \%$ above baseline. This may reflect a similar degree of receptor activation produced by the two concentrations. It is possible that the lower NMDA concentration saturates available receptors or other transduction mechanisms. Given that we are measuring trans-synaptic effects of NMDA receptor stimulation, it is also possible that excitatory inputs to basal forebrain (or locally within cortex) are similar following the perfusion of each concentration of NMDA, and that these inputs, rather than the degree of NMDA receptor activity, are limiting the amount of ACh released. Pilot studies in our laboratory have revealed that perfusions of $75 \mu \mathrm{M}$ NMDA are insufficient to stimulate ACh efflux. We are currently determining whether concentrations between 75 and $150 \mu \mathrm{M}$ NMDA will yield an elevation of ACh release that is significant but less than that seen following 150 or $250 \mu \mathrm{M}$ NMDA.

The NMDA-induced increase in cortical ACh release was, unexpectedly, seen under baseline conditions. This effect stands in contrast to previous experiments with NMDA infusions into basal forebrain in which stimulation of cortical ACh release only occurred following concomitant activation with a behavioral stimulus (Fadel et al., 2001). NMDA receptor activation is both ligand and voltage dependent, which suggests that additional sources are providing local depolarization in the NAC following NMDA perfusions. NMDA receptor activation has been shown to be dependent on depolarization by AMPA and metabotropic glutamate receptors (Hu \& White, 1998; Taverna \& Pennartz, 2003), though there may be influences other than glutamate impacting NMDA activity as well. For example, intraaccumbens activation of DA receptors increases glutamate transmission (Dalia et al., 1998), and this may serve as a source of necessary depolarization.

The neuronal circuitry underlying the ability of NMDA receptors in NAC to stimulate ACh release in PFC is presently unknown. A priori, there are several possibilities. As discussed in the Introduction, NMDA (and dopamine) receptors modulate the firing rates of GABAergic projections, which in turn regulate the excitability of basal forebrain neurons (Mogenson et al., 1983). Basal forebrain neurons can then regulate cortical ACh release directly via cholinergic projections from substantia innominata to the entire neocortical mantle (Zaborszky et al., 1999; Semba, 2000). The basal forebrain can also affect cortical ACh release indirectly via a ventral pallidal-thalamocortical circuit (Maurice et al., 1997). Local increases in AMPA receptor activity have recently been shown to increase ACh release in prefrontal and posterior parietal cortex (Nelson et al., 2005), and this glutamate receptor activity could arise, in part, from thalamic inputs. NAC efferents could also indirectly affect cortical ACh release via recurrent projections to the VTA. The VTA could then, in turn, influence basal forebrain excitability via dopaminergic projections to PFC (Seamans \& Yang, 2004). In this regard, local D1 receptor activity has recently been shown to modulate ACh efflux in PFC
(Laplante et al., 2004). We are currently conducting experiments to assess the relative contributions of basal forebrain and VTA in the stimulatory affects of accumbens NMDA on cortical ACh efflux. We are also conducting control experiments to determine whether diffusion of NMDA out of the shell to other regions of the NAC or dorsal striatum would be sufficient to stimulate cortical ACh release, although the efferent projections of the shell to both the basal forebrain and the VTA make perfusions in this area the likely locus of action.

\section{Antagonism of $D 1$ receptors interacts with the concentration of NMDA}

Although there may be a lack of dose responsivity between the two concentrations of NMDA, differences are seen when considering each concentration's interaction with the D1 antagonist. Differential interactions between NMDA and SCH-23390 were very clear, as administration of SCH-23390 significantly attenuated the NMDAinduced increase from the lower concentration of NMDA, but had no effect on ACh efflux following the higher concentration of NMDA. Local NMDA receptor activity has been shown to stimulate dopamine release within NAC (Grace, 1991; Floresco et al., 2001; Howland et al., 2002), and this may contribute to the ability of D1 receptor activity to modulate the effects of NMDA on cortical ACh release. While the mechanisms remain to be specified, our present data suggest that the higher concentration of NMDA was sufficient to stimulate NAC efferents regulating ACh release, whereas the lower concentration required some positive modulation by $\mathrm{D} 1$ receptors in order to achieve much of its impact on cortical ACh release. It remains possible, however, that a higher concentration of SCH-23390 might be required to attenuate the effects of $250 \mu \mathrm{M}$ NMDA. However, $100 \mu \mathrm{M}$ of SCH-23390 has been recently shown to attenuate the ability of perfused NMDA $(250 \mu \mathrm{M})$ to stimulate locomotor behavior and local dopamine release (Zornoza et al., 2005). It also remains possible, although not likely, that the effects of SCH-23390 reflected the drug's ability to affect 5HT receptors (Alburges et al., 1992; Millan et al., 2001). A test of this hypothesis will require the use of a more selective D1 receptor antagonist.

The exact mechanisms underlying the cooperativity between D1 receptor activity and the lower concentration of NMDA in modulating cortical ACh release are yet to be determined. It is certainly possible that this cooperative interaction begins at the level of common NAC efferents. NAC medium spiny projection neurons contain ionotropic (NMDA, AMPA/kainate) and metabotropic glutamate receptors, as well as D1, D2, D3 and D4 receptors (Jongen-Relo et al., 1995; Tarazi et al., 1998; Lu et al., 1999). These inputs converge in close proximity to one another on the dendrites of NAC medium spiny projection neurons (Sesack \& Pickel, 1990). Such a dense innervation allows for rich and complex interactions between glutamate and dopamine in the NAC. The cooperative modulation seen in this experiment is consistent with a number of other studies that have characterized NAC D1 and NMDA interactions at several levels of analysis. At the level of receptor-linked transduction mechanisms, D1 receptors regulate the affinity of the NMDA receptor by increasing the phosphorylation and decreasing the dephosphorylation (via a PKA/DARP-32/PP-1 pathway) of the NR1 subunit of the NMDA receptor (Snyder et al., 1998). D1 receptors have also been shown to regulate the trafficking of NMDA receptors in striatum (Dunah \& Standaert, 2001) and also AMPA receptors in NAC (Chao et al., 2002). In hippocampus, there is evidence of an even more direct D1-NMDA receptor interaction as D1 receptors are involved in the inhibition of NMDA-mediated excito- 
toxicity via actions on NMDA-gated currents (Lee et al., 2002). At the level of target cell excitability, D1 receptors potentiate NMDAmediated excitation of medium spiny projection neurons in dorsal striatum (see Cepeda \& Levine, 1998 for review) and in NAC (Goto \& O'Donnell, 2001a,b; West \& Grace, 2002; Charara \& Grace, 2003; O'Donnell, 2003). Finally, positive interactions between D1 and NMDA receptors have been demonstrated at the level of locomotor activity, instrumental responding and conditioned reinforcement (Burns et al., 1994; Smith-Roe \& Kelley, 2000).

\section{The complexities of accumbens glutamate receptor mediation of cortical ACh release}

The ability of NMDA receptor activation to increase cortical ACh efflux is surprising given a recent report from our laboratory demonstrating that blockade of ionotropic glutamate receptors (NMDA and/or AMPA/kainate) in the NAC increased ACh release in PFC (Neigh-McCandless et al., 2002). Importantly, these iGluR antagonists were perfused through similar probes directed at identical coordinates as in the present study. Thus, the seemingly contradictory results do not likely reflect methodological differences. An inspection of the literature reveals other reports of apparent paradoxical neurochemical and behavioral effects of local administration of NMDA and NMDA antagonists. For example, intra-NAC infusions of both NMDA (Svensson et al., 1994) and NMDA antagonists (Ault \& Werling, 1999) have been reported to increase local dopamine release. At the behavioral level, locomotor activity is enhanced following intra-NAC infusions of either NMDA (Svensson et al., 1994; David et al., 2004) or NMDA antagonists (Kelley \& Throne, 1992; David et al., 2004).

The puzzling results of our experiments on NMDA mediation of cortical ACh release, and the above studies on dopamine release or locomotor activity, are only contradictory if one presumes that the infused or perfused drugs are acting at precisely the same receptors. While possible, the likelihood that multiple receptors (subtypes with different NR2 compositions) located on several populations of NAC neurons (e.g. interneurons, medium spiny projection neurons to basal forebrain or to VTA) are differentially stimulated by bolus or perfused administration of NMDA agonists and antagonists is considerable. With respect to our finding that both NMDA and CPP stimulate cortical ACh release, we are currently testing the hypothesis that NMDA agonists and antagonists exert similar effects on cortical cholinergic transmission via their influence on different populations of NAC interneurons or efferents that directly or indirectly regulate cortical ACh release (see above).

\section{Functional implications}

The NAC has long been shown to be critical as an integrator of limbic and motor information (Kelley, 1999), in reward circuits (see Deadwyler et al., 2004) and in the attribution of incentive salience (Berridge \& Robinson, 1998). In these roles, it seems appropriate that information processing within the NAC influences both motor output and cognitive processes. The ability of NAC efferents to modulate motor output has been well documented over the past several decades (for review, see Tzschentke \& Schmidt, 2000). In addition, the convergence of excitatory information from cortex, hippocampus and amygdala in NAC has also become the focus of recent studies (Groenewegen et al., 1999; O'Donnell, 1999; Grace, 2000). It is vital that this convergence of information then modulates the detection and selection of subsequent stimuli for processing, and this involves the recruitment of attentional resources. The ability of dopaminergic and glutamatergic transmission in NAC to modulate cortical ACh release may be a chemoanatomical representation of such recruitment.

In conclusion, the present studies demonstrate that $\mathrm{D} 1$ receptors are stimulated following perfusion of NMDA into the NAC and that this stimulation contributes significantly to the ability of certain concentrations of NMDA to increase cortical ACh release. As such, these findings contribute to a large body of data revealing a positive modulation of NMDA receptors by D1 receptors in NAC. The novelty of the present study is the demonstration that this modulation is expressed trans-synaptically at the level of cholinergic transmission within the PFC. Further research is required to uncover the complexities of these interactions, and to determine the contribution of these interactions to the allocation of attention and the processing of behaviorally relevant stimuli.

\section{Acknowledgements}

This research was supported by the following grants: MH57436, MH63114, NS37026 and KO2MH10172.

\section{Abbreviations}

ACh, acetylcholine; aCSF, artificial cerebrospinal fluid; GABA, $\gamma$-aminobutyric acid; HPLC, high-performance liquid chromatography; NAC, nucleus accumbens; NMDA, $N$-methyl-D-aspartate; PFC, prefrontal cortex; TTX, tetrodotoxin; VTA, ventral tegmental area.

\section{References}

Alburges, M.E., Hunt, M.E., McQuade, R.D. \& Wamsley, J.K. (1992) D1receptor antagonists: comparison of $[3 \mathrm{H}] \mathrm{SCH} 39166$ to $[3 \mathrm{H}] \mathrm{SCH} 23390$. J. Chem. Neuroanat., 5, 357-366.

Arnold, H.M., Burk, J.A., Hodgson, E.M., Sarter, M. \& Bruno, J.P. (2002) Differential cortical acetylcholine release in rats performing a sustained attention task versus behavioral control tasks that do no explicitly tax attention. Neuroscience, 114, 451-460.

Ault, D.T. \& Werling, L.L. (1999) Phencyclidine and dizocilpine modulate dopamine release from nucleus accumbens via sigma receptors. Eur. J. Pharmacol., 386, 145-153.

Berridge, K.C. \& Robinson, T.E. (1998) What is the role of dopamine in reward: hedonic impact, reward learning, or incentive salience? Brain Res. Brain Res. Rev., 28, 309-369.

Bruno, J.P., Sarter, M., Arnold, H.M. \& Himmelheber, A.M. (1999) In vivo neurochemical markers of cognitive processes: methodological and conceptual challenges. Rev. Neurosci., 10, 25-49.

Burns, L.H., Everitt, B.J., Kelley, A.E. \& Robbins, T.W. (1994) Glutamatedopamine interactions in the ventral striatum: role in locomotor activity and responding with conditioned reinforcement. Psychopharmacology, 115, 516-528.

Cepeda, C. \& Levine, M.S. (1998) Dopamine and m-methyl-d-aspartate receptor interactions in the neostriatum. Dev. Neurosci., 20, 1-18.

Chao, S.Z., Ariano, M.A., Peterson, D.A. \& Wolf, M.E. (2002) D1 dopamine receptor stimulation increases GluR1 surface expression in nucleus accumbens neurons. J. Neurochem., 83, 704-712.

Charara, A. \& Grace, A.A. (2003) Dopamine receptor subtypes selectively modulate excitatory afferents from the hippocampus and amygdala to rat nucleus accumbens neurons. Neuropsychopharmacology, 28, 14121421.

Chen, K.C., Baxter, M.G. \& Rodefer, J.S. (2004) Central blockade of muscarinic cholinergic receptors disrupts affective and attentional setshifting. Eur. J. Neurosci., 20, 1081-1088.

Chudasama, Y., Dalley, J.W., Nathwani, F., Bouger, P. \& Robbins, T.W. (2004) Cholinergic modulation of visual attention and working memory: dissociable effects of basal forebrain 192-IgG-saporin lesions and intraprefrontal infusions of scopolamine. Learn. Mem., 11, 78-86.

Dalia, A., Uretsky, N.J. \& Wallace, L.J. (1998) Dopaminergic agonists administered into the nucleus accumbens: effects on extracellular glutamate and on locomotor activity. Brain Res., 788, 111-117. 
Dalley, J.W., Cardinal, R.N. \& Robbins, T.W. (2004a) Prefrontal executive and cognitive functions in rodents: neural and neurochemical substrates. Neurosci. Biobehav. Rev., 28, 771-784.

Dalley, J.W., McGaughy, J., O'Connell, M.T., Cardinal, R.N., Levita, L. \& Robbins, T.W. (2001) Distinct changes in cortical acetylcholine and noradrenaline efflux during contingent and noncontingent performance of a visual attentional task. J. Neurosci., 21, 4908-4914.

Dalley, J.W., Theobald, D.E., Bouger, P., Chudasama, Y., Cardinal, R.N. \& Robbins, T.W. (2004b) Cortical cholinergic function and deficits in visual attentional performance in rats following $192 \mathrm{IgG}$-saporin-induced lesions of the medial prefrontal cortex. Cereb. Cortex, 14, 922-932.

David, H.N., Kheira, S. \& Abraini, J.H. (2004) Modulation of locomotor responses induced by $\mathrm{D}_{1}$-like and $\mathrm{D}_{2}$-like dopamine receptor agonists and D-amphetamine by NMDA and non-NMDA glutamate receptor agonists and antagonists in the core of the rat nucleus accumbens. Neuropsychopharmacology, 46, 179-191.

Deadwyler, S.A., Hayashizaki, S., Cheer, J. \& Hampson, R.E. (2004) Reward, memory, and substance abuse: functional neuronal circuits in the nucleus accumbens. Neurosci. Biobehav. Rev., 27, 703-714.

Del Arco, A. \& Mora, F. (2001) Dopamine release in the prefrontal cortex during stress is reduced by the local activation of glutamate receptors. Brain Res. Bull., 15, 125-130.

Dunah, A.W. \& Standaert, D.G. (2001) Dopamine D1 receptor-dependent trafficking of striatal NMDA glutamate receptors to the postsynaptic membrane. J. Neurosci., 21, 5546-5558.

Fadel, J., Sarter, M. \& Bruno, J.P. (2001) Basal forebrain glutamatergic modulation of cortical acetylcholine release. Synapse, 39, 201-212.

Floresco, S.B., Todd, C.L. \& Grace, A.A. (2001) Glutamatergic afferents from the hippocampus to the nucleus accumbens regulate activity of ventral tegmental area dopamine neurons. J. Neurosci., 21, 4915-4922.

Franken, I.H. (2003) Drug craving and addiction: integrating psychological and neuropsychopharmacological approaches. Prog. Neuropsychopharmacol. Biol. Psychiatry, 27, 563-579.

Ghitza, U.E., Fabbricatore, A.T., Prokopenko, V.F. \& West, M.O. (2004) Differences between accumbens core and shell neurons exhibiting phasic firing patterns related to drug seeking behavior during discriminativestimulus task. J. Neurophysiol., 93, 1608-1614.

Goto, Y. \& O'Donnell, P. (2001a) Synchronous activity in the hippocampus and nucleus accumbens in vivo. J. Neurosci., 24, 121-131.

Goto, Y. \& O'Donnell, P. (2001b) Network synchrony in the nucleus accumbens in vivo. J. Neurosci., 27, 4498-4504.

Grace, A.A. (1991) Phasic versus tonic dopamine release and the modulation of dopamine system responsivity: a hypothesis for the etiology of schizophrenia. Neuroscience, $\mathbf{4 1}, 1-24$.

Grace, A.A. (2000) Gating of information flow within the limbic system and the pathophysiology of schizophrenia. Brain Res. Rev., 31, 330-341.

Groenewegen, H.J., Mulder, A.B., Beijer, A.V.J., Wright, C.I., Lopes da Silva, F.H. \& Pennartz, C.M.A. (1999) Hippocampal and amygdaloid interactions in the nucleus accumbens. Psychobiology, 27, 149-164.

Hahn, B., Sarples, C.G.V., Wonnacott, S., Shoaib, M. \& Stolerman, I.P. (2003) Attentional effects of nicotinic agonists in rats. Neuropharmacology, 44, 1054-1067.

Himmelheber, A.M., Sarter, M. \& Bruno, J.P. (2000) Increases in cortical acetylcholine release during sustained attention performance in rats. Cogn. Brain Res., 9, 313-325.

Howland, J.G., Taepavarapruk, P. \& Phillips, A.G. (2002) Glutamate receptordependent modulation of dopamine efflux in the nucleus accumbens by basolateral, cut not central, nucleus of the amygdale in rats. J. Neurosci., 22, $1137-1145$.

Hu, X. \& White, F.J. (1998) Glutamate receptor regulation of rat nucleus accumbens neurons in vivo. Synapse, 23, 208-218.

Huang, T., Yang, L., Gitzen, J., Kissinger, P.T., Vreeke, M. \& Heller, A. (1995) Detection of basal acetylcholine in rat brain microdialysate. J. Chromatogr., 670, 323-327.

Jongen-Relo, A.L., Docter, G.J., Jonke, R.A.J. \& Voorn, P. (1995) Differential localization of mRNAs encoding dopamine D1 or D2 receptors in cholinergic neurons in the core and shell of the rat nucleus accumbens. Brain Res. Mol. Brain Res., 28, 169-174.

Kelley, A.E. (1999) Neural integrative activities of nucleus accumbens subregions in relation to learning and motivation. Psychobiology, 27, 198-213.

Kelley, A.E. \& Throne, L.C. (1992) NMDA receptors mediate the behavioral effects of amphetamine infused into the nucleus accumbens. Brain Res. Bull., 29, 247-254.

Koller, G., Satzger, W., Adam, M., Wagner, M., Kathmann, N., Soyka, M. \& Engel, R. (2003) Effects of scopolamine on matching to sample paradigm and related tests in human subjects. Neuropsychobiology, 48, 87-94.

Kozak, R., Bruno, J.P. \& Sarter, M. (2005) Augmentation of attentional performance-associated increases in prefrontal acetylcholine release during basal forebrain NMDA receptor blockade-induced impairments in performance. Cereb. Cortex., in press.

Kumari, V., Gray, J.A., ffytche, D.H., Mitterschiffthaler, M.T., Das, M., Zachariah, E., Vythelingum, G.N., Williams, S.C.R., Simmons, A. \& Sharma, T. (2003) Cognitive effects of nicotine in humans: an fMRI study. Neuroimage, 19, 1002-1013.

Laplante, F., Srivastava, L.K. \& Quirion, R. (2004) Alterations in dopaminergic modulation of prefrontal cortical acetylcholine release in post-pubertal rats with neonatal ventral hippocampal lesions. J. Neurochem., 89, 314-323.

Lee, F.J.S., Xue, S., Pei, L., Vukusic, B., Chery, N., Wang, Y., Wang, Y.T. \& Niznik, H.B., Yu, X. \& Liu, F. (2002) Dual regulation of NMDA receptor functions by direct protein-protein interactions with the dopamine D1 receptor. Cell, 111, 219-230.

Legault, M. \& Wise, R.A. (1999) Injections of n-methyl-d-aspartate into the ventral hippocampus increase extracellular dopamine in the ventral tegmental area and nucleus accumbens. Synapse, 31, 241-249.

Lorrain, D.S., Baccei, C.S., Bristow, L.J., Anderson, J.J. \& Varney, M.A. (2003) Effects of ketamine and N-methyl-D-aspartate on glutamate and dopamine release in the rat prefrontal cortex: modulation by a group II selective metabotropic glutamate receptor agonist LY379268. Neuroscience, 117, 697-706.

Lu, X.Y., Chasemzadeh, M.B. \& Kalivas, P.W. (1999) Expression of glutamate receptor subunit/subtype messenger RNAS for NMDAR1, GluR1, GluR2 and mGLuR5 by accumbal projection neurons. Mol. Brain Res., 63, 287296.

Marti, M., Mela, F., Bianchi, C., Beani, L. \& Morari, M., (2002) Striatal dopamine-NMDA receptor interactions in the modulation of glutamate release in the substantia nigra pars reticulate in vivo: opposite role for D1 and D2 receptors. J. Neurochem., 83, 635-644.

Mauri, M., Sinforiani, E., Reverberi, F., Merlo, P. \& Bono, G. (1994) Pramiracetam effects on scopolamine-induced amnesia in healthy volunteers. Arch. Gerontol. Geriatr., 18, 133-139.

Maurice, N., Deniau, J.M., Menetrey, A., Glowinski, J. \& Thierry, A.M. (1997) Position of the ventral pallidum in the rat prefrontal cortex-basal ganglia circuit. Neuroscience, 80, 523-534.

McGaughy, J., Kaiser, T. \& Sarter, M. (1996) Behavioral vigilance following infusions of 192 IgG-saporin into the basal forebrain: selectivity of the behavioral impairment and relation to cortical AchE-positive fiber density. Behav. Neurosci., 110, 247-265.

Millan, M.J., Newman-Tancredi, A., Quentric, Y. \& Cussac, D. (2001) The selective dopamine D1 receptor antagonist, SCH 23390, is a potent and high efficacy agonist at cloned human serotonin2C receptors. Psychopharmacology, 156, 58-62.

Mogenson, G.J., Jones, D.L. \& Yim, C.Y. (1980) From motivation to action: functional interface between the limbic system and the motor system. Prog. Neurobiol., 14, 69-97.

Mogenson, G.J., Swanson, L.W. \& Wu, M. (1983) Neural projections from nucleus accumbens to globus pallidus, substantia innominata, and lateral preoptica-lateral hypothalamic area: an anatomical and electrophysiological investigation in the rat. J. Neurosci., 1, 189-202.

Mogenson, G.J. \& Yang, C.R. (1991) The contribution of basal forebrain to limbic-motor integration and the mediation of motivation to action. Adv. Exp. Med. Biol., 295, 267-290.

Moore, H., Fadel, J., Sarter, M. \& Bruno, J.P. (1999) Role of accumbens and cortical dopamine receptors in the regulation of cortical acetylcholine release. Neuroscience, $\mathbf{8 8}, 811-822$.

Moore, H., Sarter, M. \& Bruno, J.P. (1992) Age-dependent modulation of in vivo cortical acetylcholine release by benzodiazepine receptor ligands. Brain Res., 596, 7-29.

Neigh, G.N., Arnold, H.M., Rabenstein, R.L., Sarter, M. \& Bruno, J.P. (2004) Neuronal activity in the nucleus accumbens is necessary for performancerelated increases in cortical acetylcholine release. Neuroscience, 123, 635645.

Neigh-McCandless, G., Kravitz, B.A., Sarter, M. \& Bruno, J.P. (2002) Ionotropic glutamate receptor blockade in the nucleus accumbens increases cortical acetylcholine release. Eur. J. Neurosci., 16, 1259-1266.

Nelson, C.L., Burk, J.A., Bruno, J.P. \& Sarter, M. (2002) Effects of acute and repeated systemic administration of ketamine on prefrontal acetylcholine release and sustained attention performance in rats. Psychopharmacology, 161, 168-179. 
Nelson, C.L., Sarter, M. \& Bruno, J.P. (2005) Prefrontal cortical modulation of acetylcholine release in posterior parietal cortex. Neuroscience, 132, 347359.

Nicola, S.M., Yun, I.A., Wakabayashi, K.T. \& Fields, H.L. (2004a) Cue-evoked firing of nucleus accumbens neurons encodes motivational significance during a discriminative stimulus task. J. Neurophysiol., 91, 1840-1865.

Nicola, S.M., Yun, I.A., Wakabayashi, K.T. \& Fields, H.L. (2004b) Firing of nucleus accumbens neurons during the consummatory phase of a discriminative stimulus task depends on previous reward predictive cues. J. Neurophysiol., 91, 1866-1882.

O'Donnell, P. (1999) Ensemble encoding in the nucleus accumbens. Psychobiology, 27, 187-197.

O'Donnell, P. (2003) Dopamine gating of forebrain neural ensembles. Eur. J. Neurosci., 17, 429-435.

Passetti, F., Dalley, J.W., O’Connell, M.T., Everitt, B.J. \& Robbins, T.W. (2000) Increased acetylcholine release in the rat medial prefrontal cortex during performance of a visual attentional task. Eur. J. Neurosci., 12, 3051-3058.

Paxinos, G. \& Watson, C. (1998) The Rat Brain in Stereotaxic Coordinates. Academic Press, New York.

Pennartz, C.M.A., Groenewegen, H.J. \& Lopes da Silva, F.H. (1994) Nucleus accumbens as a complex of functionally distinct neuronal ensembles: an integration of behavioural, electrophysiological and anatomical data. Progess Neurobiol., 42, 719-761.

Potter, P.E., Meek, J.L. \& Neff, N.H. (1983) Acetylcholine and choline in neuronal tissue measured by HPLC with electrochemical detection. J. Neurochem., 41, 188-194.

Rebec, G.W., Grabner, C.P., Johnson, M., Pierce, R.C. \& Bardo, M.T. (1997) Transient increases in catecholaminergic activity in medial prefrontal cortex and nucleus accumbens shell during novelty. Neuroscience, 76, 707-714.

Sarter, M., Bruno, J.P. \& Givens, B. (2003) Attentional function of cortical cholinergic inputs: what does it mean for learning and memory? Neurobiol. Learn. Mem., 80, 245-256.

Sarter, M., Givens, B. \& Bruno, J.P. (2001) The cognitive neuroscience of sustained attention: where top-down meets bottom-up. Brain Res. Rev., 35, $146-160$.

Schoenbaum, G., Chiba, A.A. \& Gallagher, M. (1998) Orbitofrontal cortex and basolateral amygdala encode expected outcomes during learning. Nat. Neurosci., 1, 155-159.

Schoenbaum, G., Chiba, A.A. \& Gallagher, M. (1999) Neural encoding in orbitofrontal cortex and basolateral amygdala during olfactory discrimination learning. J. Neurosci., 19, 1876-1884.

Schultz, W., Tremblay, K. \& Hollerman, J.R. (2003) Changes in behaviorrelated neuronal activity in the striatum during learning. Trends Neurosci., 26, 321-328.

Seamans, J.K. \& Yang, C.R. (2004) The principal features and mechanisms of dopamine modulation in the prefrontal cortex. Prog. Neurobiol., 74, 1-58.

Semba, K. (2000) Multiple output pathways of the basal forebrain: organization, chemical heterogeneity, and roles in vigilance. Behav. Brain Res., 115, $117-141$
Sesack, S.R. \& Pickel, V.M. (1990) In the rat medial nucleus accumbens, hippocampal and catecholaminergic terminals converge on spiny neurons and are in opposition to each other. Brain Res., 527, 266-279.

Smith-Roe, S.L. \& Kelley, A.E. (2000) Coincident activation of NMDA and dopamine D1 receptors within the nucleus accumbens core is required for appetitive instrumental learning. J. Neurosci., 20, 7737-7742.

Snyder, G.L., Fienberg, A.A., Huganir, R.L. \& Greengard, P. (1998) A dopamine/D1 receptor/protein kinase A/dopamine- and cAMP- regulated phosphoprotein $\left(\mathrm{M}_{\mathrm{r}} 32 \mathrm{kDa}\right) /$ protein phosphatase-1 pathway regulates dephosphorylation of the NMDA receptor. J. Neurosci., 18, 10297-10303.

Svensson, L., Zhang, J., Johannessen, K. \& Engel, J.A. (1994) Effect of local infusion of glutamate analogues into the nucleus accumbens of rats: an electrochemical and behavioural study. Brain Res., 643, 155-161.

Tarazi, F.I., Campbell, A., Yeghiayan, S.K. \& Baldessarini, R.J. (1998) Localization of ionotropic glutamate receptors in caudate-putamen and nucleus accumbens septi of rat brain: comparison of NMDA, AMPA, and kainate receptors. Synapse, 30, 227-235.

Taverna, S. \& Pennartz, C.M.A. (2003) Postsynaptic modulation of AMPAand NMDA-receptor currents by Group III metabotropic glutamate receptors in rat nucleus accumbens. Brain Res., 976, 60-68.

Tzschentke, T.M. \& Schmidt, W.J. (2000) Functional relationship among medial prefrontal cortex, nucleus accumbens, and ventral tegmental area in locomotion and reward. Crit. Rev. Neurobiol., 14, 131-142.

Vasey, M.W. \& Thayer, J.F. (1987) The continuing problem of false positives in repeated measures ANOVA in psychophysiology: a multivariate solution. Psychophysiology, 24, 479-486.

Vezina, P. \& Kim, J.H. (1999) Metabotropic glutamate receptors and the generation of locomotor activity: interactions with midbrain dopamine. Neurosci. Biobehav. Rev., 23, 577-589.

West, A.R. \& Grace, A.A. (2002) Opposite influences of endogenous dopamine D1 and D2 receptor activation on activity states and electrophysiological properties of striatal neurons: studies combining in vivo intracellular recordings and reverse microdialysis. J. Neurosci., 22, 294-304.

Yun, I.A., Nicola, S.M. \& Fields, H.L. (2004a) Contrasting effects of dopamine and glutamate receptor antagonist injection in the nucleus accumbens suggest a neural mechanism underlying cue-evoked goal-directed behavior. Eur. J. Neurosci., 20, 249-263.

Yun, I.A., Wakabayashi, K.T., Fields, H.L. \& Nicola, S.M. (2004b) The ventral tegmental area is required for the behavioral and nucleus accumbens neuronal firing responses to incentive cues. J. Neurosci., 24, 2923-2933.

Zaborszky, L. \& Cullinan, W.E. (1992) Projections from the nucleus accumbens to cholinergic neurons of the ventral pallidum: a correlated light and electron microscopic double-immunolabeling study in rat. Brain Res., 570, 92-101.

Zaborszky, L., Pang, K., Somogyi, J., Nadasdy, Z. \& Kalli, I. (1999) The basal forebrain corticopetal system revisited. Ann. NY Acad. Sci., 877, 339-367.

Zornoza, T., Cano-Cebrian, M.J., Miquel, M., Aragon, C., Polache, A. \& Granero, L. (2005) Hippocampal dopamine receptors modulate the motor activation and the increase in dopamine levels in the rat nucleus accumbens evoked by chemical stimulation of the ventral hippocampus. Neuropsychopharmacology, 30, 843-852. 